\title{
Liquid Phase Catalytic Oxidation of Aqueous Solutions That Contain Organic Matter in a Trickle-Bed Reactor
}

\author{
Canan Uraz*, Süheyda Atalay \\ Chemical Engineering Department, Faculty of Engineering, Ege University, Bornova, Turkey \\ Email: *canan.uraz@ege.edu.tr
}

Received November 11, 2012; revised December 10, 2012; accepted December 20, 2012

\begin{abstract}
In this study, catalytic wet air oxidation of wastewater that contains organic matter (phenol) is investigated in a laboratory scale trickle-bed reactor. The aim of this project is to determine the optimum operating conditions for the reaction of phenol in the wastewater with oxygen using a catalyst. For this purpose, the effects of temperature, gas flow rate, liquid space velocity and initial concentration of phenol on the conversion of phenol at constant pressure and the effect of pressure on the conversion of phenol at constant temperature are investigated. An industrial copper chromite catalyst was used in the experimental studies. It is seen from the experimental results, conversion of phenol increases with increasing temperature, pressure, gas flow rate and liquid space velocity; and also, it is seen that conversion of phenol decreases with increasing initial concentration of phenol. The conversion of phenol reaches at $130^{\circ} \mathrm{C}$ and 4 bar to $40 \%$. It was also found that, $3 \mathrm{ppm}$ copper amount was determined from the exit stream of the reactor. This result shows that cupper placed in the structure of the catalyst, mixes with the liquid stream during the reaction.
\end{abstract}

Keywords: Catalytic Oxidation; Phenol; Trickle-Bed Reactor

\section{Introduction}

Disposal of waste water is acquiring increasing importance all over the world, due to the progressively more restrictive environmental constraints. This generates the need to develop effective treatment technologies for different kinds of wastes. Phenol and its derivatives, which are present in many waste water streams, must be specifically treated because of their extreme toxicity for aquatic life. Among the different methods to remove phenol from aqueous wastes, solvent extraction is only economically attractive if the phenol concentration is high enough, i.e. over $1 \%$. Likewise, biological treatment is only appropriate for low phenol concentrations due to the bactericide properties of the phenolic compounds, even at concentrations as low as $0.001 \%$. Thus, chemical oxidation emerges as a promising route for phenol removal at intermediate concentrations [1]. Oxidation techniques such as incineration, ozonation, wet air oxidation photocatalytic oxidation, supercritical wet oxidation, aerobic coupling or electrochemical oxidation have been used for phenol removal. However, the severe operation conditions and the investment needed in the most cases have prevented them from being widely implemented. Thus, the development of nonexpensive but efficient routes for phenol oxidation is still a challenge in the last

${ }^{*}$ Corresponding author. decade [1]. Wet air or thermal liquid phase oxidation (WAO) process is known to have a great potential for the treatment of effluents containing a high content of organic matter (chemical oxygen demand (COD) 10 - 100 $\mathrm{g} / \mathrm{l}$ ), or toxic contaminants for which direct biological purification is unfeasible. However, the reaction conditions required to achieve oxidation in this aqueous phase flameless combustion technique are severe, typically being in the range of $473-573 \mathrm{~K}$ and $70-130$ bar, which adversely affects the cost-benefit of this process. Under such extreme conditions, most materials for construction are susceptible to stress corrosion cracking when chloride ions are present in the waste stream. Compared to conventional wet air oxidation, catalytic wet air oxidation (CWAO) offers lower energy requirements and much higher oxidation efficiencies [2]. For optimal effect, a catalytic liquid phase oxidation process should be installed at the source of wastewater production in an industrial plant. Depending on the type and amount of organic compounds dissolved in wastewater, the process can be designed either to reduce their concentration or ultimately destroy them. In the former case, the intermediate products formed during the oxidation must be biodegradable. For reactions necessitating a solid catalyst and involving both relatively volatile (oxygen) and nonvolatile reactants (pollutant in wastewater stream), threephase reactors are required [3]. There are many types of 
reactor that were mostly used for CWAO; packed bed reactors, slurry reactors (agitated ones or bubble-slurry columns), monolithic reactors and trickle-bed reactor [4-11].

In this study, catalytic wet air oxidation of wastewater that contains organic matter (phenol) was investigated in a laboratory scale trickle-bed reactor. The aim of this project is to determine the optimum operating conditions for the reaction of phenol in the wastewater with oxygen using a catalyst. For this purpose, the effects of temperature, gas flow rate, liquid space velocity and initial concentration of phenol on the conversion of phenol at constant pressure and the effect of pressure on the conversion of phenol at constant temperature were investigated.

\section{Experimental Study}

\subsection{Experimental Set-Up}

The flow diagram of the experimental set-up used in this study is shown in Figure 1. All parts of the set-up were made of 316 stainless steel.

\subsubsection{Preheater}

Preheater is a stainles steel pipe in which aqueous phenol solution pass through. Preheater is heated using a $\mathrm{Ni}-\mathrm{Cr}$ electrical wire that surrounds the pipe and the given heat to the heater is adjusted by a variac.

\subsubsection{Reactor}

Reactor has four parts with a diameter of $4.2 \mathrm{~cm}$. The height of each part is $5 \mathrm{~cm}$. The first part is distributor that has holes to distribute liquid and gas. Distributor is shown in Figure 2. The second part is an inert part which is filled with glass rings. The third part is the catalyst bed. The tested catalyst is replaced in this part. The last part is the second inert part. The reactor is surrounded with a $\mathrm{Ni}-\mathrm{Cr}$ electrical wire, the temperature into reactor bed is measured by a thermocouple and is controlled by a temperature controller type of PID. A needle valve is re-

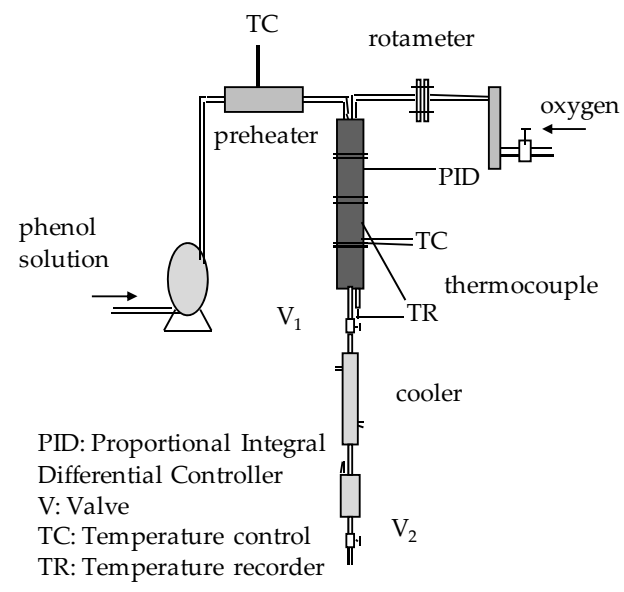

Figure 1. Experimental set-up.

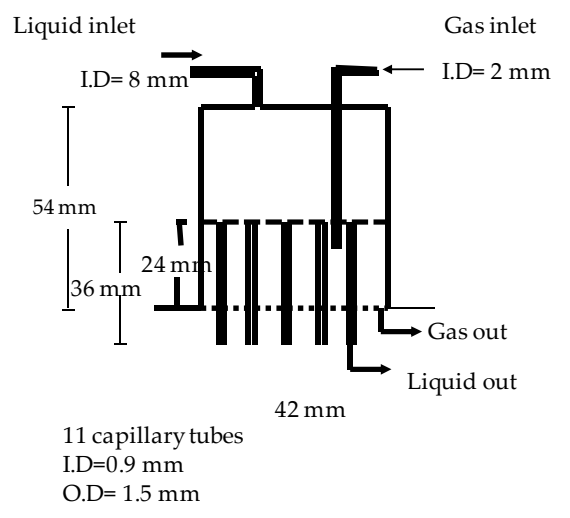

Figure 2. Liquid distributor.

placed on the outlet pipe of the reactor to adjust the operating pressure of the system and the pressure is measured using a manometer. The oxygen required for the reaction is maintained using an oxygen cylinder and its flowrate is adjusted by a rotameter.

\subsubsection{Cooler}

A double pipe heat exchanger is used as cooler to cool the effluent stream coming from the reactor and ethanolwater mixture cooled by a cryostat is used as cooling medium. The cooled liquid stream including water and unreacted phenol is collected into a product tank and the samples are taken at the selected period of time.

\subsection{Adjustment of the Reactants}

The reactants are phenol and oxygen. Oxygen is obtained from gas cylinder and the flow rate of it is adjusted with a flow meter. Prepared phenol solution is pumped to the reactor by a digital piston pump. Some physical properties of phenol is given in Table 1.

\subsection{Catalyst}

The catalyst used in the experimental study was a commercial catalyst (Copper chromite) with a code of $\mathrm{Cu}$ 0203 and it was supplied by the company Engelhard. The active component in the catalyst is $\mathrm{CuO}$ and it has a composition of $67 \%-77 \% \mathrm{CuO}, 20 \%-30 \%$ copper chromite and $1 \%$ - 3\% synthetic graphite. It has the following properties:

Shape and size: Cylindrical, 1/8";

Surface area: $10 \mathrm{~m}^{2}$;

Total pore volume: $0.1 \mathrm{~cm}^{2} / \mathrm{g}$;

Packed bed density: $2 \mathrm{~g} / \mathrm{cm}^{3}$.

\subsection{Start-Up and Operation}

The temperature of the reactor and preheater were set to the desired value. Circulation of the cooling fluid (ethylalcohol + water mixture) was started. After the temperature attained the desired value, pump was turned on 
Table 1. Physical properties of phenol.

\begin{tabular}{lc}
\hline Molecular weight & $94.144 \mathrm{~g} / \mathrm{mol}$ \\
\hline Freezing point & $40.91^{\circ} \mathrm{C}$ \\
Normal boiling point & $181.84^{\circ} \mathrm{C}$ \\
Heat of fusion & $122.2 \mathrm{~J} / \mathrm{g}$ \\
Heat of vaporization at boiling point & $487.9 \mathrm{~J} / \mathrm{g}$ \\
Heat of combustion & $-32.428 \mathrm{~J} / \mathrm{g}$ \\
Viscosity at $100^{\circ} \mathrm{C}$ & $1.09 \mathrm{~mm}^{2} / \mathrm{s}$ \\
Specific heat at $22.7^{\circ} \mathrm{C}$ (solid) & $1.41 \mathrm{~J} / \mathrm{gK}$ \\
At $70^{\circ} \mathrm{C}-74^{\circ} \mathrm{C}$ (liquid) & $2.22 \mathrm{~J} / \mathrm{gK}$ \\
Flash point temperature closed cup & $79^{\circ} \mathrm{C}$ \\
Temperature open cup & $85^{\circ} \mathrm{C}$ \\
Critical temperature & $419^{\circ} \mathrm{C}$ \\
Critical pressure & $6.11 \mathrm{MPa}$ \\
Density at $60^{\circ} \mathrm{C}$ (liquid) & $1.0413 \mathrm{~g} / \mathrm{cm}^{3}$ \\
\hline
\end{tabular}

and the flow rate of nitrobenzene was adjusted. Nitrobenzene solution was pumped to the reactor. Oxygen flow rate was adjusted by the valve on the calibrated rotameter and sent to the reactor. The effluent passed through the cooler and then it went through the traps. The uncondensed gas was purged to the atmosphere. At the end of experiment (after two hours), the pump was switched off. The product, collected in the trap at each experiment, was analysed by Hewlett Packard 5890 Series II Gas Chromatograph with flame ionization dedector and HP integrator. A polar capillary column (HPFFAP, $25 \mathrm{~m} \times 0.32 \mathrm{~mm} \times 0.52 \mu \mathrm{m}$ ) was used, nitrogen was the carrier gas for the analyses. The temperatures of injection and detector were $160^{\circ} \mathrm{C}$ and $250^{\circ} \mathrm{C}$, respectively. After each experiment the catalyst was activated at adjusted temperature with low hydrogen flow in one hour.

\subsection{Experiments}

Experiments were performed using commercial catalyst to test the performance of copper oxide on the oxidation of phenol solution. $15 \mathrm{~g}$ of Copper Chromite catalyst was loaded into the reactor and series of experiments were made. In Table 2, the reaction conditions of these experiments are listed. Conversion of phenol was calculated by using following equation:

$$
x_{\mathrm{Fenol}}=\left(\frac{C_{\mathrm{Fenol}, 0}-C_{\mathrm{Fenol}, t}}{C_{\mathrm{Fenol}, 0}}\right) \times 100
$$

\section{Results and Discussion}

Wet air oxidation of phenol solution was investigated in a trickle bed reactor at different operating conditions.

In the first group experiments, temepereture effect on the reaction was investigated. It is seen from Figure 3 that, conversion was obtained around $23 \%$ at $110^{\circ} \mathrm{C}$, but
Table 2. Operation conditions of the experiments.

\begin{tabular}{ccccccc}
\hline Exp. No P (Bar) & $\mathrm{T}\left({ }^{\circ} \mathrm{C}\right)$ & $\begin{array}{c}\text { Qoxygen. } \\
(\mathrm{ml} / \mathrm{min})\end{array}$ & $\begin{array}{c}\text { Space } \\
\text { velocity } \\
(\mathrm{g} \text { cat. s/mol })\end{array}$ & $\begin{array}{c}C_{\text {Phenol,0 }} \\
(\mathrm{mg} / \mathrm{l})\end{array}$ & $\begin{array}{c}\text { Time } \\
(\mathrm{min})\end{array}$ \\
\hline 1 & 4 & 110 & 333 & 125786.2 & 500 & 150 \\
2 & 4 & 120 & 333 & 125786.2 & 500 & 150 \\
3 & 4 & 130 & 333 & 125786.2 & 500 & 150 \\
4 & 4 & 130 & 268 & 125786.2 & 500 & 150 \\
5 & 4 & 130 & 209 & 125786.2 & 500 & 150 \\
6 & 4 & 130 & 333 & 251572.3 & 500 & 240 \\
7 & 4 & 130 & 333 & 83857.4 & 500 & 150 \\
8 & 4 & 130 & 333 & 125786.2 & 1000 & 150 \\
9 & 4 & 130 & 333 & 125786.2 & 1500 & 150 \\
10 & 5 & 130 & 333 & 125786.2 & 500 & 150 \\
\hline
\end{tabular}

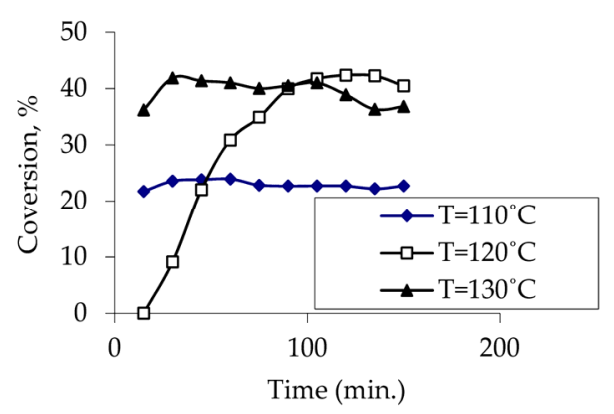

Figure 3. Effect of temperature on phenol conversion at constant pressure $(P=4$ bar $)$, at oxygen flow rate $(Q=333$ $\mathrm{ml} / \mathrm{min})$, at space velocity (125786.2 $\mathrm{g}$ cat. $\mathrm{s} / \mathrm{mol})$ and at initial concentration of phenol (500 mg/l).

it was around $40 \%$ at the other temperatures. So it can be said that conversion increases with increasing temperature at constant pressure.

In the second group experiments, flow rate of oxygen was changed to see the effect of the oxygen flow rate on phenol conversion at constant temperature and pressure. According to the results of these experiments, it was seen that conversion increases with increasing oxygen flow rate. So it can explained that, to obtain high conversion values, high oxygen flow rate values should be used. It can be seen from Figure 4.

In Figure 5, it is shown that the effect of space velocity to the conversion. The flow rate of phenol solution was changed at constant catalyst amount to obtain the space velocity values. When the results of the experiments compared with each other, it was found that lower conversion values were obtained at space velocity was $83857.4 \mathrm{~g}$ cat. $\mathrm{s} / \mathrm{mol}$ (liquid flow rate $=1.5 \mathrm{ml} / \mathrm{min}$ ), but in the other experiments the conversion values were close to each other. So it can be said that, the liquid flow rate should be in the range of $0.5-1 \mathrm{ml} / \mathrm{min}$. at constant catalyst loading in this experiment system.

In the fourth group experiments, just initial concentration 


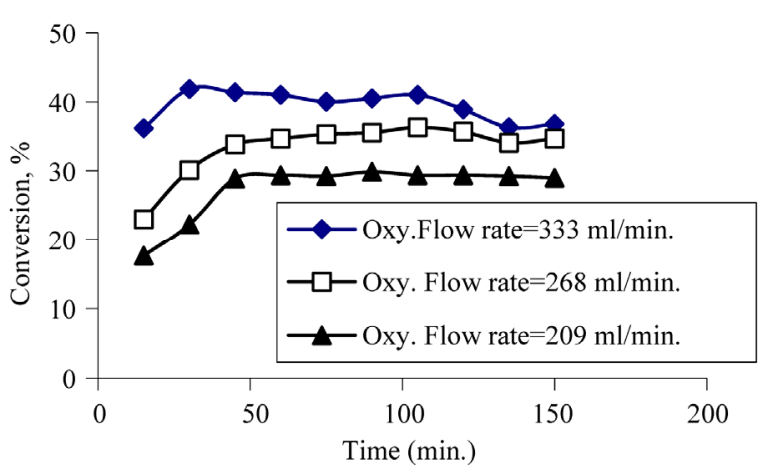

Figure 4. Effect of oxygen flow rate on to conversion at constant pressure $(4 \mathrm{bar})$, at temperature $\left(130^{\circ} \mathrm{C}\right)$, at space velocity $(125786.2 \mathrm{~g}$ cat. $\mathrm{s} / \mathrm{mol})$ and at initial concentration of phenol (500 mg/l).

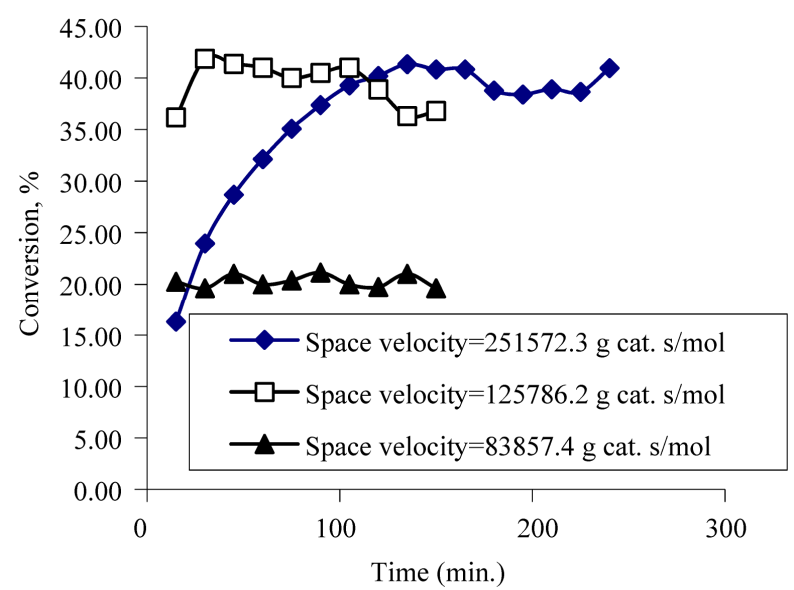

Figure 5. Effect of space velocity on conversion at constant pressure (4 bar), at temperature $\left(130^{\circ} \mathrm{C}\right)$, at oxygen flow rate $(333 \mathrm{ml} / \mathrm{min})$ at initial concentration of phenol $(500 \mathrm{mg} / \mathrm{l})$.

of phenol was changed and the other parameters were kept constant. According to the Figure 6, it can be seen that, the highest conversion is obtained at the lowest initial concentration of phenol.

The other group experiments were obtained to see the effect of the pressure. The experiments were investigated at pressures 4 and 5 bar. According to the results of these experiments, it can found that conversion values obtained at 5 bar were a little bit higher than the conversion values obtained at 4 bar. The effect of pressure on conversion is seen in Figure 7. The experiments should be obtained at higher pressure values to see the effect of pressure on the reaction.

To investigate the activity of catalyst, some analysis were obtained. The samples obtained at the end of each experiment were analyzed at atomic absorption to determine the cupper amount in the catalyst structure. It was found that, cupper in the liquid stream was determined at cupper analysis obtained at the end of each experiment. This result shows that cupper placed in the structure of

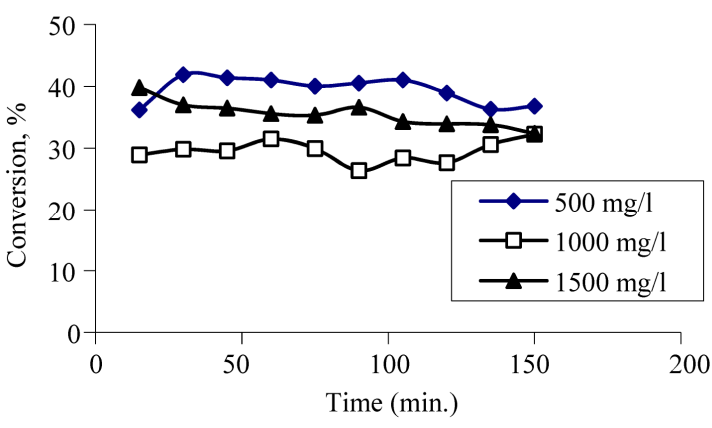

Figure 6. Effect of initial concentration of phenol on conversion at constant pressure, temperature, oxygen flow rate and at initial concentration of phenol.

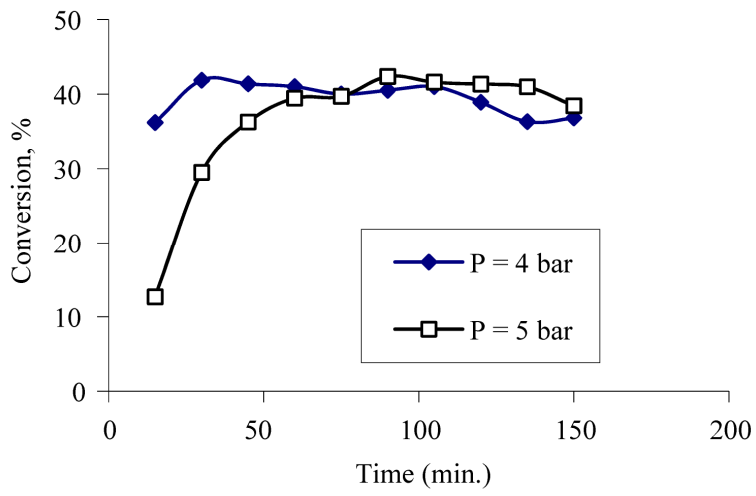

Figure 7. Effect of pressure on conversion at constant, temperature, oxygen flow rate and initial concentration of phenol.

Table 3. Cupper amounts in the liquid stream at the end of each experiments.

\begin{tabular}{cc}
\hline Exp. No & Cupper amount (ppm) \\
\hline 1 & 0.734 \\
2 & 6.038 \\
3 & 1.966 \\
4 & 0.829 \\
5 & 0.603 \\
6 & 0.697 \\
7 & 0.381 \\
8 & 0.397 \\
9 & 0.349 \\
10 & 3.527 \\
\hline
\end{tabular}

the catalyst, mixes with the liquid stream during the reaction. Cupper amounts are given in Table 3.

\section{REFERENCES}

[1] J. Font, C. Bengoa, A. Fortuny, A. Alejandre, C. Miro and A. Fabregat, "Agueous Phase Catalytic Oxidation of Phenol in a Trickle Bed Reactor: Effect of the $\mathrm{pH}$," Water 
Research, Vol. 33, No. 4, 1998, pp. 1005-1013.

[2] J. Levec and A. Pintar, "Catalytic Oxidation on Aqueous Solutions of Organic. An Effective Method for Removal of Toxic Pollutants from Waste Waters," Catalysis Today, Vol. 24, No. 1-2, 1995, pp. 51-58. doi:10.1016/0920-5861(95)00006-2

[3] A. Pintar, G. Bercic and J. Levec, "Catalytic Liquid Phase Oxidation of Aqueous Phenol Solutions in a Trickle BedReactor," Chemical Engineeing Science, Vol. 52, No. 2122, 1997, pp. 4143-4153.

[4] A. Cybulski and J. Trawczynski, "Catalytic Wet Air Oxidation of Phenol over Platinum and Ruthenium Catalysts," Applied Catalysis B: Environmental, Vol. 47, No. 1, 2004, pp. 1-13. doi:10.1016/S0926-3373(03)00327-8

[5] S. T. Kolaczkowski and S. Awdry, "The Condensation/ Polymerisation of Dimethyl Siloxane Fluids in a ThreePhase Trickle Flow Monolith Reactor," Catalysis Today, Vol. 69, No. 1-4, 2001, pp. 275-281. doi:10.1016/S0920-5861(01)00380-7

[6] K. K. Pant, A. Singh and K. D. P. Nigam, "Catalytic Wet Oxidation of Phenol in a Trickle Bed Reactor," Chemical Engineering Journal, Vol. 103, No. 1-3, 2004, pp. 51-57. doi:10.1016/j.cej.2004.06.006

[7] F. Stuber, A. Eftaxias, J. Font, A. Fortuny and A. Fa- bregat, "Catalytic Wet Air Oxidation of Phenol over Active Carbon Catalyst: Global Kinetic Modelling Using Simulated Annealing," Applied Catalysis B: Environmental, Vol. 67, No. 1-2, 2006, pp. 12-23.

[8] A. Fabregat, A. Fortuny, C. Bengoa, J. Font and F. Castells, "Water Pollution Abatement by Catalytic Wet Air Oxidation in a Trickle Bed Reactor," Catalysis Today, Vol. 53, No. 1, 1999, pp. 107-114. doi:10.1016/S0920-5861(99)00106-6

[9] A. Santos, P. Yustos, A. Quintanilla, S. Rodriguez and F. Garcia-Ochoa, "Route of the Catalytic Oxidation of Phenol in Aqueous Phase," Applied Catalysis B: Environmental, Vol. 39, No. 2, 2002, pp. 97-113. doi:10.1016/S0926-3373(02)00087-5

[10] M. Al-Dahhan and J. Guo, "Catalytic Wet Air Oxidation of Phenol in Cocurrent Downflow and Upflow PackedBed Reactor over Pillared Clay Catalyst," Chemical Engineering Science, Vol. 60, No. 3, 2005, pp. 735-746. doi:10.1016/j.ces.2004.08.043

[11] C. Hung and W. Lin, "Catalytic Wet Air Oxidation of Aqueous Solutions of Ammonia in a Continuous-Flow Trickle-Bed Reactor Over Metal Supported on Carbon Materials," Sustainable Environment Research, Vol. 20, No. 4, 2010, pp. 251-255. 